\title{
Work and fatigue characteristics of unsuited and suited humans during isolated isokinetic joint motions
}

\author{
L. JAVIER GONZALEZ $\dagger$, J. C. MAIDA $\S^{*}$, E.H. MILES $\ddagger$ \\ S.L. RAJULU†† and A.K. PANDYA $\ddagger$ \\ $\dagger$ SPACEHAB, Houston, Texas \\ $\S$ (P.I.) NASA Johnson Space Center, Houston, Texas \\ \$lockheed Engineering \& Sciences Company, Houston, Texas \\ $\dagger \dagger$ NSBRI, Houston, Texas
}

\begin{abstract}
Keywords: Joint fatigue; Joint strength; Task planning; Extra-Vehicular Activity (EVA); Extra-vehicular Mobility Unit (EMU)
\end{abstract}

The effects of a pressurized suit on human performance were investigated. The suit is known as an Extra-vehicular Mobility Unit (EMU) and is worn by astronauts while working outside of their space craft in low earth orbit. Isolated isokinetic joint torques of three female and three male subjects (all experienced users of the suit) were measured while working at $100 \%$ and $80 \%$ of their maximum voluntary torque (MVT). It was found that the average decrease in the total amount of work done when the subjects were wearing the EMU was $48 \%$ and $41 \%$ while working at $100 \%$ and $80 \%$ MVT, respectively. There is a clear relationship between the MVT and the time and amount of work done until fatigue. In general the stronger joints took longer to fatigue and did

\footnotetext{
*Author for correspondence. E-mail: jim.maida@jsc.nasa.gov
} 
more work than the weaker joints. However, it is not clear which joints are most affected by the EMU suit in terms of the amount of work done. The average amount of total work done increased by $5.2 \%$ and $20.4 \%$ for the unsuited and suited cases, respectively, when the subject went from working at $100 \%$ to $80 \%$ MVT. Also, the average time to fatigue increased by $9.2 \%$ and $25.6 \%$ for the unsuited and suited cases, respectively, when the subjects went from working at $100 \%$ to $80 \%$ MVT. The EMU also decreased the joint range of motion. It was also found that the experimentally measured torque decay could be predicted by a logarithmic equation. The absolute average error in the predictions was found to be $18.3 \%$ and $18.9 \%$ for the unsuited and suited subject, respectively, working at $100 \%$ MVT, and $22.5 \%$ and $18.8 \%$ for the unsuited and suited subject, respectively, working at $80 \%$ MVT. These results could be very useful in the design of future EMU suits, and planning of Extra-Vehicular Activity (EVA) for the upcoming International Space Station assembly operations.

\section{Introduction}

With the upcoming International Space Station assembly missions, EVA will increase dramatically. Approximately 900 EVA hours will be required to assemble the Space Station with an additional 200 hours per year for maintenance requirements. Task planning could increase the efficiency of the suited astronaut while performing ExtraVehicular Activities (EVAs). Efficient task planning could be facilitated by a simulation using a three-dimensional human model with proper range of motion (ROM), strength, and fatigue characteristics for all the major joints of the body. 
While no comprehensive database exists which contains strength and fatigue measurements for all the isolated joints of an unsuited and suited astronaut, much research has been done to investigate the ergonomic characteristics of unsuited and suited astronauts (O’Hara 1989; Shafer et al. 1992; Bishu and Klute 1993; Poliner et al. 1993, 1994; Rajulu and Klute 1993; Rajulu et al. 1993; Bishu et al. 1994; Wilmington et al. 1994; Morgan et al. 1996, Rajulu et al. 1998). One objective of this study was to acquire and analyze experimental data for unsuited and suited humans while performing isolated joint motions for all the major joints of the upper body (the upper body joints are the ones most commonly used to perform EVAs). It is desirable, in particular, to study the differences in the time to fatigue and total work done on a joint-by-joint basis, for suited and unsuited humans, in order to compare and evaluate suit designs. An additional longterm objective is to develop a predictive model for work and fatigue (Pandya et al. 1992a). This requires identifying and quantifying a trend in the torque decay over time for each joint axis direction. Quantifying this torque decay is an objective of the present research. The torque decay trend in conjunction with a maximum available torque model (Pandya et al. 1992b) can be used to predict work and fatigue. This model could then be integrated into a model for simulation and optimization of tasks in suited and unsuited conditions.

\section{Experiments}

\subsection{Subjects}

Three female and three male subjects were used in the experiments. The low subject count was due to time constraints. First, the availability of a suit and a qualified subject 
at the same point in time was limited. Second, time spent wearing the suit was a constraint, being generally two to three hours for one session, thus creating the need for many sessions per subject with the additional session set up time. Third, because we were measuring fatigue, additional time per subject was required in order to reach the $50 \%$ MVT threshold and to allow for subject recovery. Finally, the subjects participating in the experiments were required to have a current Air Force Class 3 physical. In order to minimize learning effects, only subjects with considerable experience in the use of the EMU were allowed to participate in the experiments. Table 1 gives a description of the test subjects.

\section{[Insert table 1 about here]}

\subsection{Test facility and equipment}

The experiments were conducted in the Precision Air Bearing Facility (PABF) at Johnson Space Center. This facility allowed for multiple test configurations through the use of its floor sled, smooth floor area, and air bearings. Extremely heavy objects mounted on top of air bearings can easily be moved around the PABF floor once the air supply to the bearings has been activated. This aided in positioning the test hardware and subjects in proper alignment for conducting the strength and fatigue tests.

Joint strength and fatigue measurements were made using a LIDO Multi-Joint II testing unit (Loredan Biomedical, Inc., West Sacramento, CA). The LIDO Multi-Joint II is an integrated system consisting of a dynamometer connected to a personal computer. The system has a series of attachments that enable strength measurements of the various joints of the human body. The system also allows setting of experimentally defined 
exercise parameters such as: velocity, ROM, and torque limits. A unique feature of the LIDO is that it incorporates a gravity compensation feature that takes into account the one-gravity artifact throughout the ROM. This capability is used to remove the effect of the weight of the LIDO attachment, EMU suit segment, and the subject's limbs from the measured torques and forces, providing the subject's actual effort.

Standard Shuttle EMU suits with external air supplies were used for these experiments. An environmental control system was also used to maintain the suit pressurization at $29.6 \mathrm{kPa}$. During testing, a floor sled was used to relieve the test subject of the mass of the suit (approximately 118 to $123 \mathrm{~kg}$ ). Figure 1 shows a suited subject during one of the tests.

[insert figure 1 about here]

\subsection{Procedure}

Since upper-body movements (e.g., locomotion using hand rails, using tools to repair objects, and moving large masses) are integral to most EVA operations, emphasis was placed on testing strength and fatigue for the major joints of the upper body. The five isolated isokinetic joint motions that were included were: (1) shoulder flexion/extension, (2) shoulder abduction/adduction, (3) shoulder internal/external rotation, (4) elbow flexion/extension, and (5) wrist flexion/extension. All of the testing was performed on the subject's right side with the subject secured in an upright (standing) posture.

The procedure to find the MVT is now described. The subject drove the LIDO attachment back and forth using maximum exertion at a prescribed angular velocity of $1.05 \mathrm{rad} / \mathrm{s}$ throughout the ROM for three non-stop repetitions. Because of time 
constraints only one angular velocity was used. The angular velocity of $1.05 \mathrm{rad} / \mathrm{s}$ was selected as the benchmark based on previous work done by Pandya et al. 1992b, which also used it as a benchmark. The variation between the three torque curves was then computed using the LIDO computer. A variation of more than ten percent was used as a measure to indicate that the subject was not using maximal exertion during the strength test. If the variation was less than ten percent, the subject's MVT for both directions of motion was computed by averaging the three peak torque values for each direction.

For the fatigue tests the subject drove the LIDO attachment repeatedly at the prescribed angular velocity of $1.05 \mathrm{rad} / \mathrm{s}$ throughout the entire ROM using the target level of exertion ( $100 \%$ or $80 \%$ of the MVT) without stopping. The subject was allowed to continue the test until the torque output in both directions dropped below the defined fatigue index value $(50 \%$ of the MVT) for three consecutive repetitions. If the subject did not reach fatigue after five minutes, the test was stopped. A five-minute rest period was allowed between joint measurements. This procedure was used for both the unsuited and suited tests.

The use of $50 \%$ of the MVT as the fatigue index requires some explanation. This number came from the work of Patton et al. 1978, which found that the use of $50 \%$ MVT as a fatigue index ensures a significant decline in function. Others have also used this protocol to denote fatigue, such as Schwendner et al. 1995 who concluded that an isokinetic fatigue test to $50 \%$ MVT, repeated three times, was an appropriate fatigue generating protocol for most active males.

\section{Results}




\subsection{Unsuited versus suited performance}

The time to fatigue presented here was computed in a manner different than the protocol used in the experiments. Here, the time to fatigue is defined as the ending time of the repetition for which the computed work done during that repetition dropped below $50 \%$ of the work done during the first repetition. This time was then used as the ending time for computing the number of repetitions, and work to fatigue. Figure 2 illustrates how the time to fatigue was computed as just described for subject 5 during elbow flexion while working at $100 \%$ of the MVT. For the case shown in figure 2, subject 5 fatigued at 73 seconds for the unsuited test, and at 53 seconds for the suited test. Figure 3 shows the mean torque per repetition, again for subject 5 during elbow flexion while working at $100 \%$ of the MVT, while figure 4 shows polar plots of the torque measurements.

[insert figures 2, 3 and 4 about here]

Tables 2 and 3 show the MVT, number of repetitions, time, and work to fatigue (for each joint motion averaged across all subjects) for the unsuited and suited subject working at $100 \%$ and $80 \%$ of their MVT, respectively. Table 4 shows the percent decrease in work done by the test subjects from unsuited to suited for each joint motion. Figures 5 and 6 show bar plots of the work done to fatigue for each joint motion averaged across all subjects working at $100 \%$ and $80 \%$ MVT, respectively.

[insert tables 2, 3, and 4 about here]

[insert figures 5 and 6 around here]

\subsection{Prediction of torque decay as a function of time}


The procedure to obtain equations to predict the torque decay as a function of time for a specific joint motion is now described. First, the mean torque for each repetition and corresponding mean time was computed. The data for all the subjects was then grouped and smoothed before it was normalized. A moving average of ten was visually found to provide sufficient smoothing of the data while keeping the characteristics of it. It was then found, by trial and error (with the use of the solver function in Microsoft Excel), that an equation of the form:

$$
\tau_{\text {norm }}=\mathrm{a}+\mathrm{b} \ln |\mathrm{t}+\mathrm{c}|
$$

where $\tau_{\text {norm }}$ is the normalized torque, $\mathrm{t}$ is time, and $\mathrm{a}, \mathrm{b}$ and $\mathrm{c}$ are coefficients, represents the torque decay quite well. Figure 7 shows the actual normalized data and curve fits for shoulder flexion for the unsuited and suited subjects working at $100 \%$ of their MVT. Table 5 gives the coefficients for equation (1) for unsuited and suited subjects working at $100 \%$ of their MVT, while table 6 gives the coefficients for equation (1) for unsuited and suited subjects working at $80 \%$ of their MVT. Given equation (1) and the maximum torque $\left(\tau_{\max }\right)$ for the first repetition of a repetitive task, the torque decay as a function of time can then be predicted by:

$$
\tau_{\mathrm{norm}}=\tau_{\max }[\mathrm{a}+\mathrm{b} \ln |\mathrm{t}+\mathrm{c}|]
$$

Using equation (2) the predictions were computed for subjects 1-6. The average absolute error in the predictions for all subjects was $18.3 \%$ for the unsuited case and $18.9 \%$ for the suited case at $100 \%$ MVT, and $22.5 \%$ for the unsuited case and $18.8 \%$ for the suited case at $80 \%$ MVT. Figure 8 shows the actual and predicted torque for subject 2 during wrist extension at $100 \%$ MVT, while figure 9 shows the actual and predicted torque for subject 3 during shoulder internal rotation at $80 \%$ MVT. 
[insert figure 7 about here]

[insert tables 5 and 6 about here]

[insert figures 8 and 9 about here]

\section{Discussion}

One objective of this study was to quantify the effects of an EMU suit on the human performance. Another objective was to develop equations that can be used to predict the torque decay for each joint motion tested. In this section, a brief discussion of the justification of the experimental and modeling procedures is provided. This is followed by a discussion of the results pertaining to the two objectives mentioned above.

\subsection{Justification of assumptions}

For the data analysis, the female and male data were grouped. In light of the fact that individuals use the same muscle groups, and that these muscle groups basically have the same shape, orientation, and points of attachment, but differ in magnitude of force exerted (Pandya et al. 1992b), it is felt that grouping of the data is justified since it was normalized. For this reason, the low number of test subjects used is also thought to be sufficient to give the trends of the work and fatigue characteristics of unsuited and suited humans during isolated isokinetic joint motions.

\subsection{Unsuited versus suited performance}

The effect of the suit on performance is clearly evident. In general, the work and mean torque per repetition decreased when the subject was suited (figures 2 and 3 , 
respectively). The joint range of motion also decreased in general for the suited subject (figure 4). The average decrease in the total amount of work done when the subjects were wearing a suit was $48 \%$ and $41 \%$ while working at $100 \%$ and $80 \%$ MVT, respectively. There is a clear relationship between the MVT and the amount of work done till fatigue. In general, the larger the MVT the more work that was done (tables 2 and 3). It is not clear as to which joints the EMU suit affects more in terms of the amount of work done. For the case with the test subjects working at $100 \%$ MVT, wrist extension and shoulder flexion are affected the most, while at $80 \%$ MVT, wrist flexion and shoulder external rotation are affected the most (table 4).

The average total amount of work done by the test subjects increased by $5.2 \%$ and $20.4 \%$ for the unsuited and suited cases, respectively, when the test subjects went from working at $100 \%$ to $80 \%$ MVT. Also, the average time to fatigue increased by $9.2 \%$ and $25.6 \%$ for the unsuited and suited cases, respectively, when the test subjects went from working at $100 \%$ to $80 \%$ MVT. These results could be very useful in the planning of EVAs.

\subsection{Prediction of torque decay as a function of time}

It was found that the torque decay could be predicted by a logarithmic equation (equation (2), figures 7,8 and 9 ). The average correlation coefficient, $\mathrm{R}^{2}$, for the curve fit for all the joint motions is 0.89 for both the unsuited and suited cases at $100 \%$ MVT, and 0.91 and 0.89 for the unsuited and suited cases, respectively, at $80 \%$ MVT, which indicates a good fit. The absolute average error in the predictions was found to be $18.3 \%$ and $18.9 \%$ for the unsuited and suited subject, respectively, working at $100 \%$ MVT, and 
$22.5 \%$ and $18.8 \%$ for the unsuited and suited subject, respectively, working at $80 \%$ MVT. As mentioned in the introduction, a torque decay trend, used in conjunction with a maximum available torque model (Pandya et al. 1992b), can be used to predict work and fatigue. This predictor can also be integrated into a three-dimensional dynamic model for analyses of tasks in both suited and unsuited conditions.

\section{Summary and future work}

The effects of an EMU on isolated joint torque were measured. Using six subjects, both suited and unsuited, isolated isokinetic joint torques were measured with the subjects working at $100 \%$ and $80 \%$ of their MVT, using $50 \%$ of the MVT as the fatigue index. It was found, on average, that the EMU reduced total work by about $50 \%$, and the larger the MVT, the longer the time to fatigue and the greater amount of work done. It was not clear which joint the EMU suit affects most. The amount of work and time to fatigue improved the most for the suited case, when the subject started at $80 \%$ MVT. The EMU also decreased the joint range of motion. It was also found that the experimentally measured torque decay trend could be predicted by a logarithmic equation with an average error of $\pm 9.3 \%$ and $\pm 10.3 \%$ for the $100 \%$ and $80 \%$ MVT cases, respectively. These results could be very useful in the design of future EMU suits, and planning of Extra-Vehicular Activity (EVA) for International Space Station assembly missions. 
Future work includes the incorporation of these results into a human three-dimensional dynamic model. 


\section{References}

BISHU, R.R. and KLUTE, G. 1993, Investigation of the effects of extravehicular activity (EVA) gloves on performance, NASA Technical Paper 3401.

BISHU, R.R., BRONKEMA, L.A., GARCIA, D., KLUTE, G. and RAJULU, S. 1994, Tactility as a function of grasp force: Effects of glove, orientation, pressure, load, and handle, NASA Technical Paper 3474.

MORGAN, D.A., WILMINGTON, R.P., PANDYA, A.K., MAIDA, J.C. and DEMEL, K.J. 1996, Comparison of extravehicular mobility unit (EMU) suited and unsuited isolated joint strength measurements, NASA Technical Report TP-3613.

O'HARA, J.M. 1989, The effect of pressure suit gloves on hand performance, Proceedings of the Human Factors Society $33^{\text {rd }}$ Annual Meeting, 139-142.

PANDYA, A.K., MAIDA, J.C., ALDRIDGE, A.M., HASSON, S.M. and WOOLFORD, B.J. 1992a, The validation of a human force model to predict dynamic forces resulting from multi-joint motions, NASA Technical Paper 3206. 
PANDYA, A.K., HASSON, S.M., ALDRIDGE, A.M. and MAIDA, J.C. 1992b, Correlation and prediction of dynamic human isolated joint strength from lean body mass, NASA Technical Paper 3207.

PATTON, R.W., HINSON, M.M., ARNOLD, B.R. and LESSARD, B. 1978, Fatigue curves of isokinetic contractions, Arch. Phys. Med. Rehabili., 59, 507-509.

POLINER, J., WILMINGTON, R.P., KLUTE, G.K. 1993, Strength capabilities and load requirements while performing torquing tasks in zero gravity, NASA Technical Paper 3433.

POLINER, J., WILMINGTON, R.P. and KLUTE, G.K. 1994, Geometry and gravity influences on strength capability, NASA Technical Paper 3511.

RAJULU, S.L., KAKAVAND, A., MULANI, K. and MAIDA, J.C. 1998, Hand strength in a simulated microgravity environment, $28^{\text {th }}$ International Conference on Environmental Systems, (Danvers, Massachusetts).

RAJULU, S.L. and KLUTE, G.K. 1993, A comparison of hand grasp breakaway strengths and bare-handed grip strengths of the astronauts, SML III test subjects, and the subjects from the general population, NASA Technical Paper 3286. 
RAJULU, S.L., POLINER, J., KLUTE, G.K. 1993, Loads produced by a suited subject performing tool tasks without the use of foot restraints, NASA Technical Paper 3424.

SCHAFER, L.E., RAJULU, S.L. and KLUTE, G.K. 1992, A comparison of two shuttle launch and entry suits: reach envelope, isokinetic strength, and treadmill tests, $22^{\text {nd }}$ International Conference on Environmental Systems, (Seattle, Washington).

SCHWENDNER, K.I., MIKESKY, A.E., WIGGLESWORTH, J.K. and BURR, D.B. 1995, Recovery of dynamic muscle function following isokinetic fatigue testing, International Journal of Sports Medicine, 16(3), 185-189.

WILMINGTON, R.P., POLINER, J. and KLUTE, G.K. 1994, Use of a pitch adjustable foot restraint system: Operator strength capability and load requirements, NASA Technical Paper 3477. 


\section{Tables}

Table 1. Description of test subjects.

\begin{tabular}{|l|c|c|c|c|c|c|}
\hline & Subject 1 & Subject 2 & Subject 3 & Subject 4 & Subject 5 & Subject 6 \\
\hline Gender & female & male & male & male & female & female \\
\hline Mass $(\mathrm{kg})$ & 59 & 77 & 86 & 66 & 68 & 54 \\
\hline Height $(\mathrm{cm})$ & 165 & 172 & 181 & 170 & 165 & 168 \\
\hline Hand dominance & right & right & left & right & right & right \\
\hline
\end{tabular}


Table 2. Repetitions, time and work to fatigue for unsuited and suited subjects working at $100 \%$ of their MVT.

\begin{tabular}{|c|c|c|c|c|c|c|c|c|}
\hline \multirow[b]{2}{*}{ Joint motion } & \multicolumn{4}{|c|}{ UNSUITED } & \multicolumn{4}{|c|}{ SUITED } \\
\hline & $|\mathrm{MVT}|(\mathbf{N} \cdot \mathbf{m})$ & Repetitions & Time (s) & Work (J) & $|\mathbf{M V T}|(\mathbf{N} \cdot \mathbf{m})$ & Repetitions & Time (s) & Work (J) \\
\hline Wrist extension & 11 & 40 & 107 & 243 & 7 & 25 & 59 & 96 \\
\hline Wrist flexion & 18 & 22 & 61 & 236 & 11 & 19 & 47 & 115 \\
\hline Elbow extension & 43 & 29 & 110 & 1199 & 34 & 30 & 83 & 769 \\
\hline Elbow flexion & 39 & 18 & 69 & 711 & 33 & 16 & 43 & 377 \\
\hline Shoulder extension & 63 & 23 & 108 & 2017 & 67 & 27 & 91 & 1134 \\
\hline Shoulder flexion & 61 & 24 & 108 & 1923 & 42 & 26 & 87 & 668 \\
\hline Shoulder abduction & 50 & 45 & 202 & 2520 & 34 & 56 & 152 & 1207 \\
\hline Shoulder adduction & 54 & 28 & 125 & 1660 & 41 & 41 & 112 & 1107 \\
\hline Shoulder external & 21 & 25 & 89 & 436 & 19 & 15 & 48 & 234 \\
\hline Shoulder internal & 39 & 30 & 108 & 1049 & 37 & 18 & 60 & 562 \\
\hline Average & 40 & 28 & 109 & 1199 & 33 & 27 & 78 & 627 \\
\hline
\end{tabular}


Table 3. Repetitions, time and work to fatigue for unsuited and suited subjects working at $80 \%$ of their MVT.

\begin{tabular}{|c|c|c|c|c|c|c|c|c|}
\hline \multirow[b]{2}{*}{ Joint motion } & \multicolumn{4}{|c|}{ UNSUITED } & \multicolumn{4}{|c|}{ SUITED } \\
\hline & $|\mathbf{M V T}|(\mathbf{N} \cdot \mathbf{m})$ & Repetitions & Time (s) & Work (J) & $|\mathbf{M V T}|(\mathbf{N} \cdot \mathbf{m})$ & Repetitions & Time (s) & Work (J) \\
\hline Wrist extension & 11 & 34 & 95 & 228 & 7 & 41 & 105 & 140 \\
\hline Wrist flexion & 18 & 30 & 79 & 324 & 11 & 26 & 63 & 99 \\
\hline Elbow extension & 43 & 34 & 149 & 1193 & 34 & 37 & 95 & 1005 \\
\hline Elbow flexion & 39 & 27 & 111 & 890 & 33 & 22 & 58 & 514 \\
\hline Shoulder extension & 63 & 32 & 148 & 2426 & 67 & 31 & 97 & 1257 \\
\hline Shoulder flexion & 61 & 19 & 84 & 1447 & 42 & 28 & 83 & 775 \\
\hline Shoulder abduction & 50 & 35 & 144 & 2327 & 34 & 69 & 152 & 1310 \\
\hline Shoulder adduction & 54 & 39 & 173 & 2095 & 41 & 62 & 148 & 1328 \\
\hline Shoulder external & 21 & 32 & 114 & 453 & 19 & 22 & 71 & 272 \\
\hline Shoulder internal & 39 & 28 & 98 & 1224 & 37 & 31 & 108 & 851 \\
\hline Average & 40 & 31 & 119 & 1261 & 33 & 37 & 98 & 755 \\
\hline
\end{tabular}


Table 4. Percent decrease in work done to fatigue from unsuited to suited case.

\begin{tabular}{|c|c|c|}
\hline Joint motion & $\mathbf{1 0 0} \%$ MVT & $\mathbf{8 0} \%$ MVT \\
\hline Wrist extension & 60 & 39 \\
\hline Wrist flexion & 51 & 69 \\
\hline Elbow extension & 36 & 16 \\
\hline Elbow flexion & 47 & 42 \\
\hline Shoulder extension & 44 & 48 \\
\hline Shoulder flexion & 65 & 46 \\
\hline Shoulder abduction & 52 & 44 \\
\hline Shoulder adduction & 33 & 37 \\
\hline Shoulder external rotation & 46 & 40 \\
\hline Shoulder internal rotation & 46 & 30 \\
\hline Average & 48 & 41 \\
\hline
\end{tabular}


Table 5. Coefficients for equation (1) and correlation coefficient $\mathrm{R}^{2}$ for $100 \% \mathrm{MVT}$.

\begin{tabular}{|c|r|r|r|r|r|r|r|r|}
\hline & \multicolumn{9}{|c|}{ Unsuited } & \multicolumn{1}{c|}{ Suited } \\
\hline Joint motion & $\mathbf{a}$ & \multicolumn{1}{|c|}{$\mathbf{b}$} & \multicolumn{1}{c|}{$\mathbf{c}$} & $\mathbf{R}^{2}$ & $\mathbf{a}$ & \multicolumn{1}{|c|}{ b } & \multicolumn{1}{c|}{$\mathbf{R}^{2}$} \\
\hline Wrist extension & 1.461 & -0.192 & 11.061 & 0.90 & 0.917 & -0.086 & -0.385 & 0.77 \\
\hline Wrist flexion & 1.268 & -0.186 & 4.211 & 0.96 & 1.345 & -0.206 & 5.325 & 0.95 \\
\hline Elbow extension & 1.208 & -0.122 & 5.502 & 0.76 & 1.568 & -0.233 & 11.416 & 0.90 \\
\hline Elbow flexion & 1.350 & -0.170 & 7.815 & 0.81 & 1.132 & -0.156 & 2.332 & 0.81 \\
\hline Shoulder extension & 1.486 & -0.200 & 11.378 & 0.91 & 1.281 & -0.154 & 6.222 & 0.86 \\
\hline Shoulder flexion & 1.468 & -0.181 & 13.367 & 0.93 & 1.345 & -0.177 & 7.017 & 0.94 \\
\hline Shoulder abduction & 1.858 & -0.239 & 36.119 & 0.89 & 1.407 & -0.171 & 10.742 & 0.94 \\
\hline Shoulder adduction & 2.257 & -0.322 & 49.292 & 0.90 & 1.291 & -0.164 & 5.924 & 0.90 \\
\hline Shoulder external rotation & 2.139 & -0.334 & 30.202 & 0.92 & 1.600 & -0.238 & 12.412 & 0.89 \\
\hline Shoulder internal rotation & 1.449 & -0.187 & 11.006 & 0.94 & 1.344 & -0.195 & 5.813 & 0.94 \\
\hline
\end{tabular}


Table 6. Coefficients for equation (1) and correlation coefficient $\mathrm{R}^{2}$ for $80 \%$ MVT.

\begin{tabular}{|c|r|r|r|r|r|r|r|r|}
\hline & \multicolumn{9}{|c|}{ Unsuited } & \multicolumn{1}{c|}{ Suited } \\
\hline Joint motion & $\mathbf{a}$ & \multicolumn{1}{|c|}{$\mathbf{b}$} & \multicolumn{1}{|c|}{$\mathbf{c}$} & $\mathbf{R}^{2}$ & $\mathbf{a}$ & \multicolumn{1}{c|}{ b } & \multicolumn{1}{c|}{$\mathbf{c}$} & $\mathbf{R}^{2}$ \\
\hline Wrist extension & 1.374 & -0.181 & 7.863 & 0.87 & 0.941 & -0.067 & -0.410 & 0.78 \\
\hline Wrist flexion & 2.189 & -0.303 & 50.797 & 0.80 & 1.332 & -0.148 & 9.367 & 0.80 \\
\hline Elbow extension & 1.662 & -0.223 & 19.534 & 0.93 & 3.061 & -0.472 & 78.713 & 0.88 \\
\hline Elbow flexion & 1.663 & -0.249 & 14.358 & 0.93 & 1.718 & -0.281 & 12.929 & 0.92 \\
\hline Shoulder extension & 1.615 & -0.214 & 17.757 & 0.93 & 2.349 & -0.347 & 49.134 & 0.94 \\
\hline Shoulder flexion & 1.427 & -0.175 & 11.424 & 0.90 & 1.132 & -0.115 & 3.143 & 0.87 \\
\hline Shoulder abduction & 2.706 & -0.372 & 98.301 & 0.91 & 1.231 & -0.115 & 7.454 & 0.90 \\
\hline Shoulder adduction & 1.534 & -0.183 & 18.503 & 0.91 & 1.145 & -0.116 & 3.500 & 0.91 \\
\hline Shoulder external rotation & 1.911 & -0.280 & 25.835 & 0.96 & 2.076 & -0.327 & 26.807 & 0.95 \\
\hline Shoulder internal rotation & 1.854 & -0.250 & 30.285 & 0.95 & 1.752 & -0.251 & 20.007 & 0.96 \\
\hline
\end{tabular}


Figures

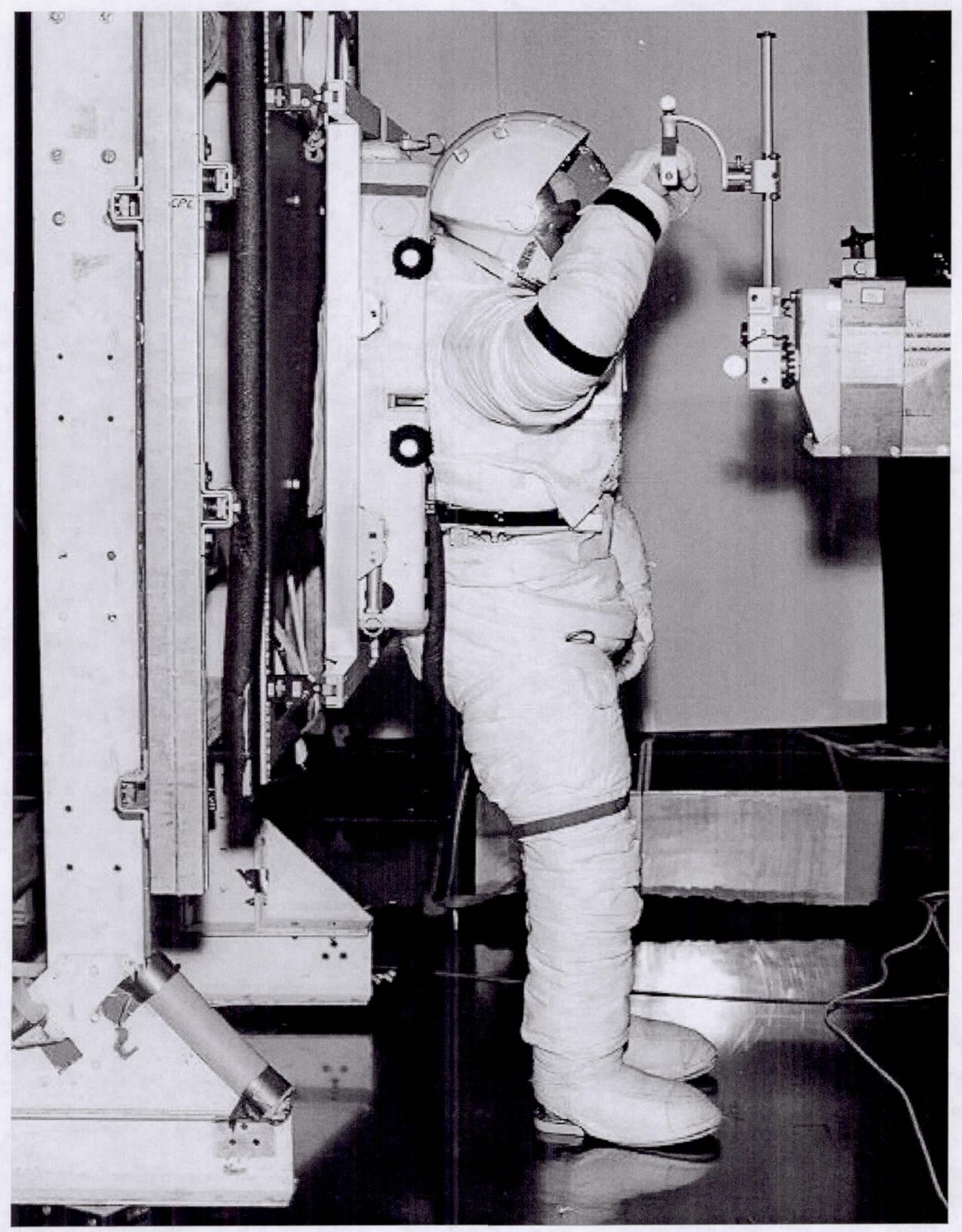

Figure 1. Suited subject with LIDO Multi-Joint II testing unit while being supported by air bearing floor sled. 


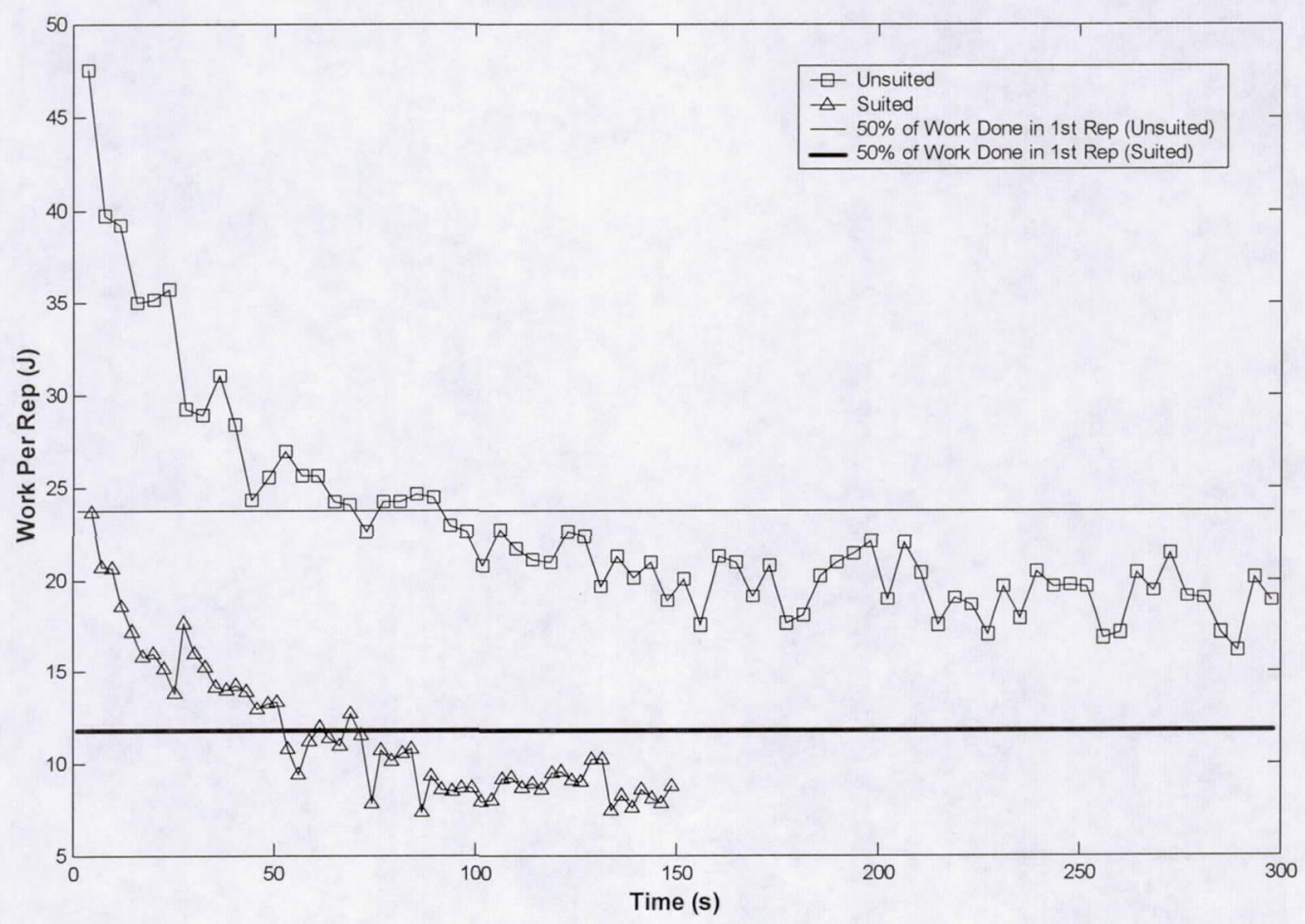

Figure 2. Work per repetition for subject 5 during elbow flexion at 100\% MVT. 


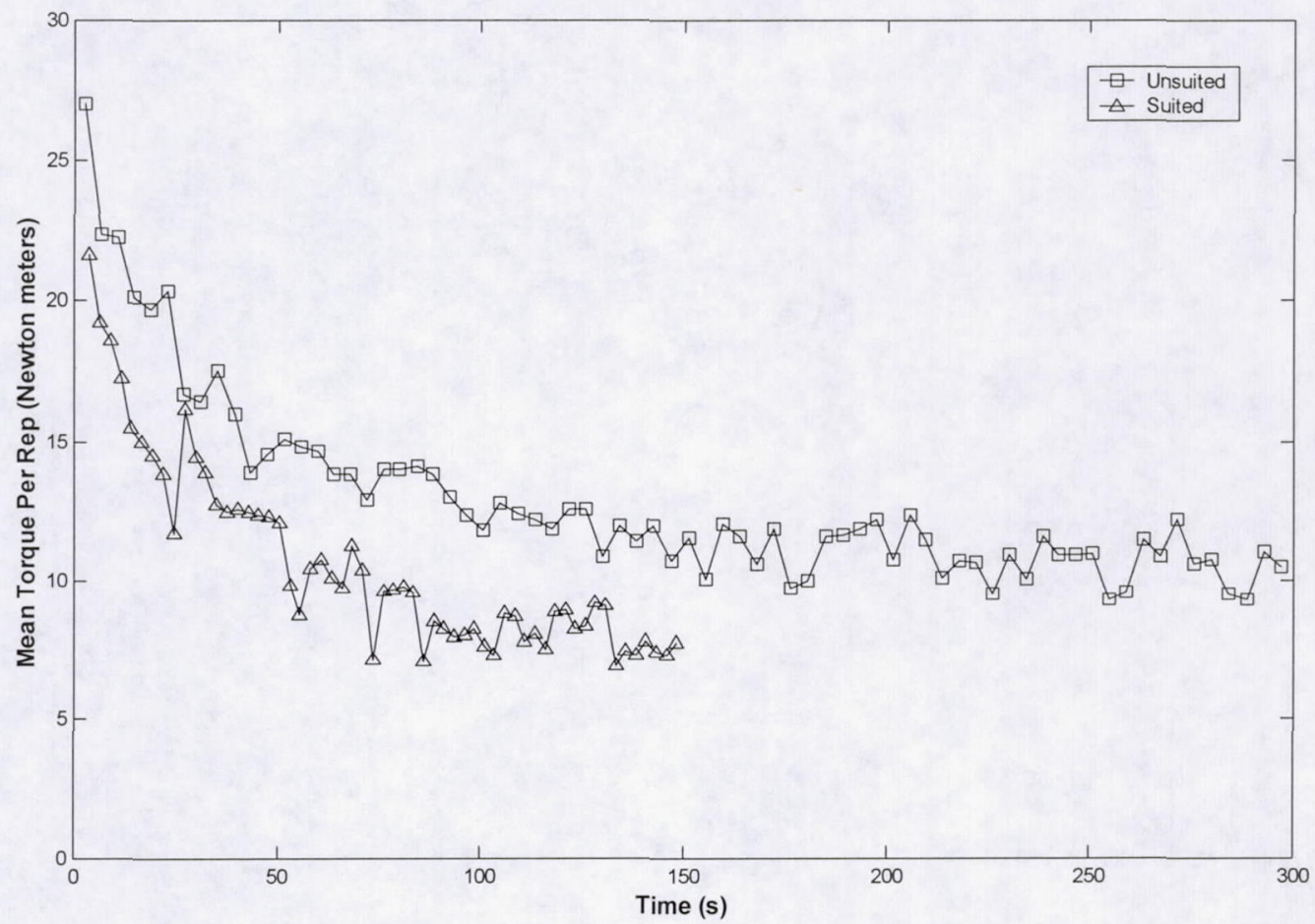

Figure 3. Mean torque per repetition for subject 5 during elbow flexion at $100 \%$ MVT. 


\section{Unsuited}

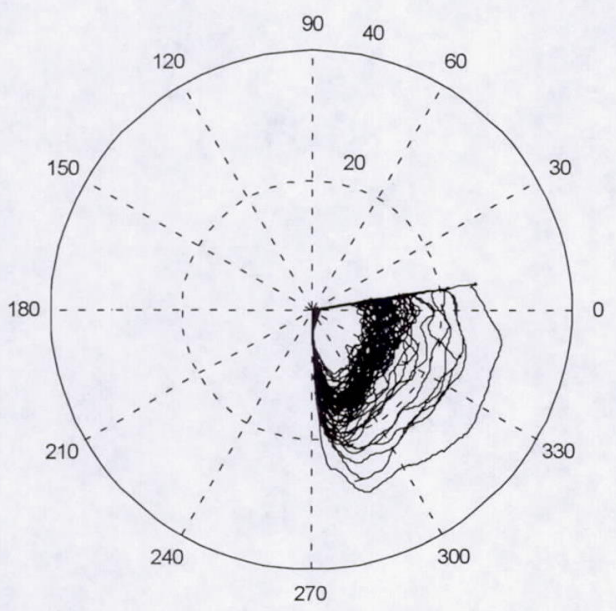

Joint Torque (Newton meters)

(a)

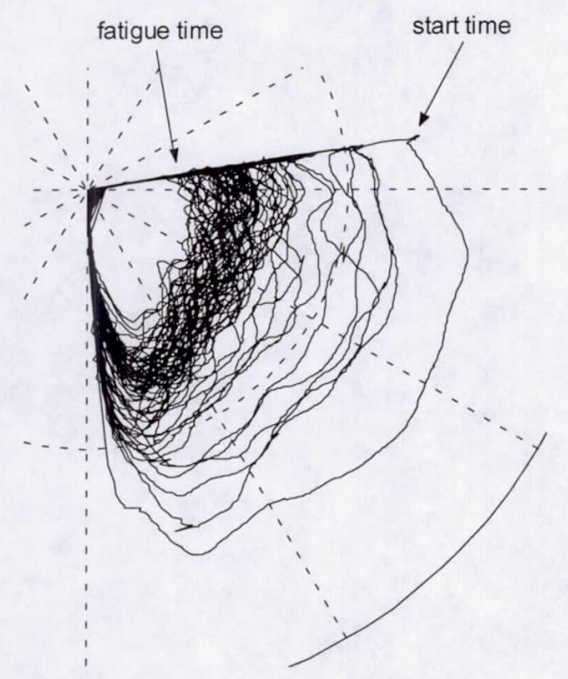

(c)

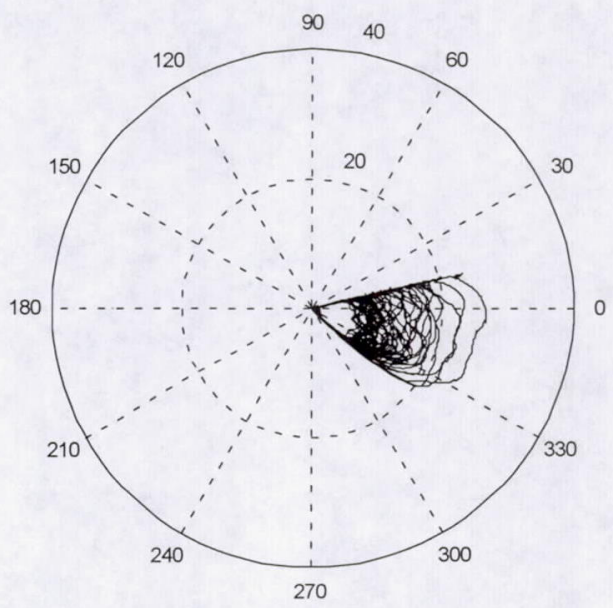

Joint Torque (Newton meters)

(b)

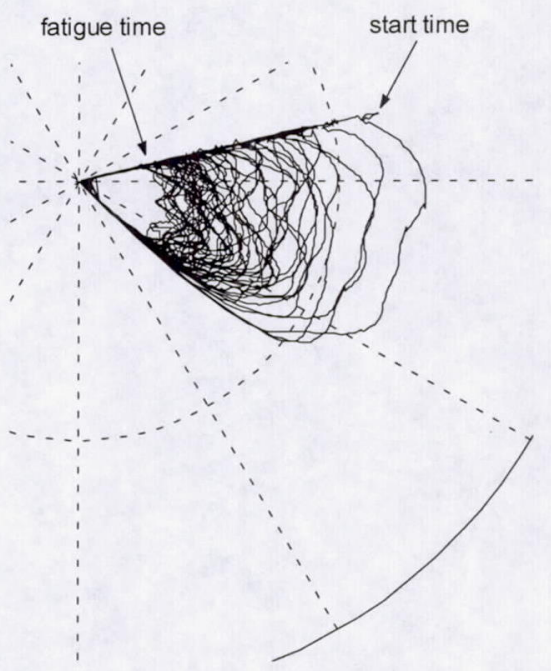

(d)

Figure 4. Polar plots of torque measurements for subject 5 during elbow flexion at $100 \%$ MVT (angles in degrees). Figures $4 c$ and $4 d$ are close up views of $4 a$ and $4 b$, respectively. 


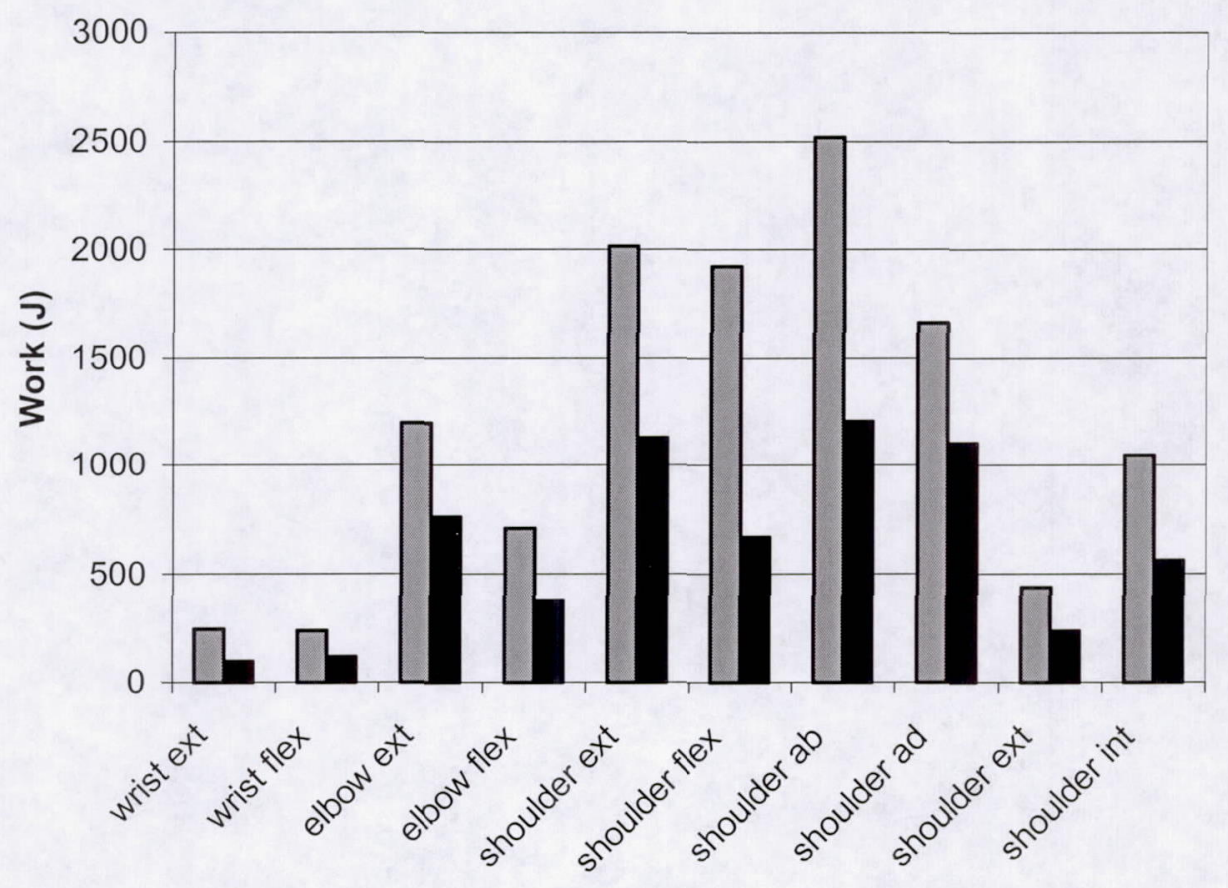

UUnsuited

- Suited

Figure 5. Work to fatigue for test subjects working at 100\% MVT. 


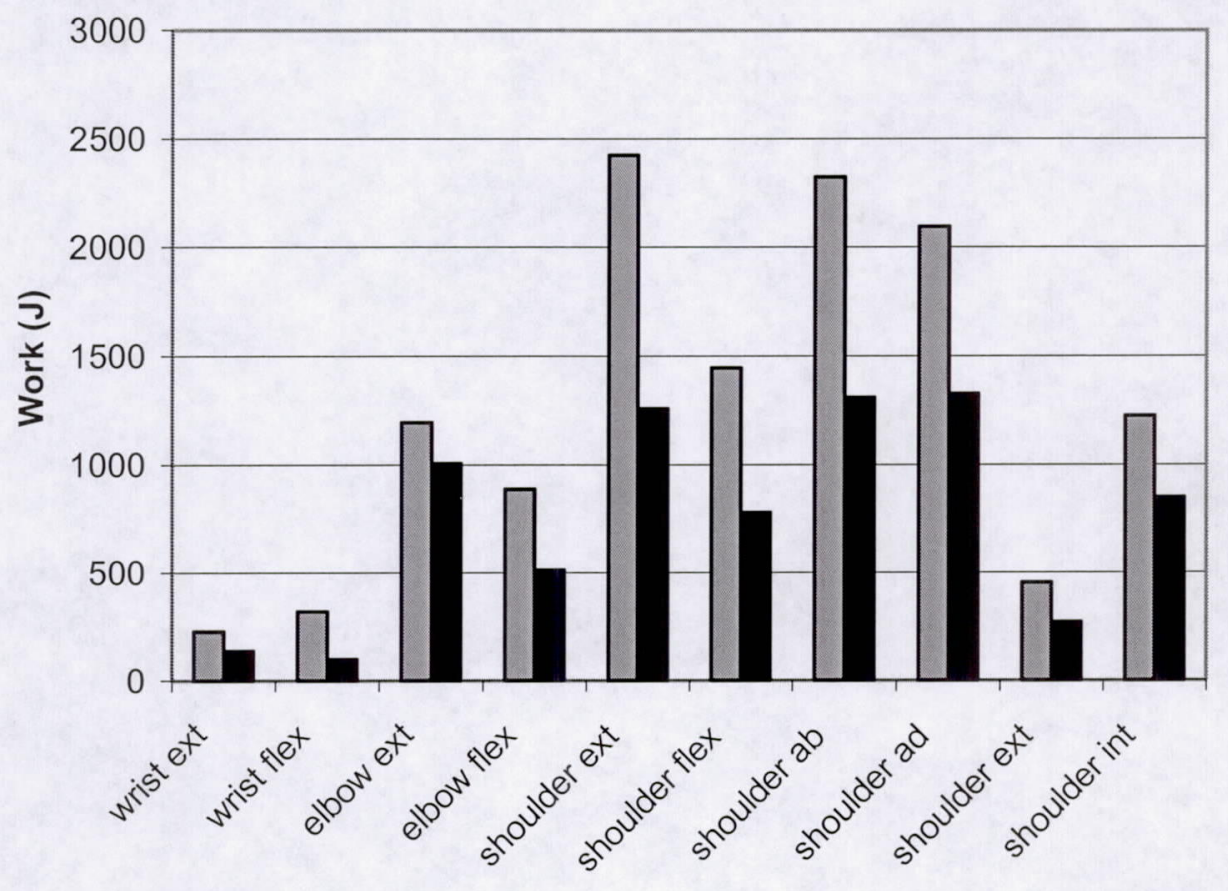

口Unsuited

回 Suited

Figure 6. Work to fatigue for test subjects working at 80\% MVT. 


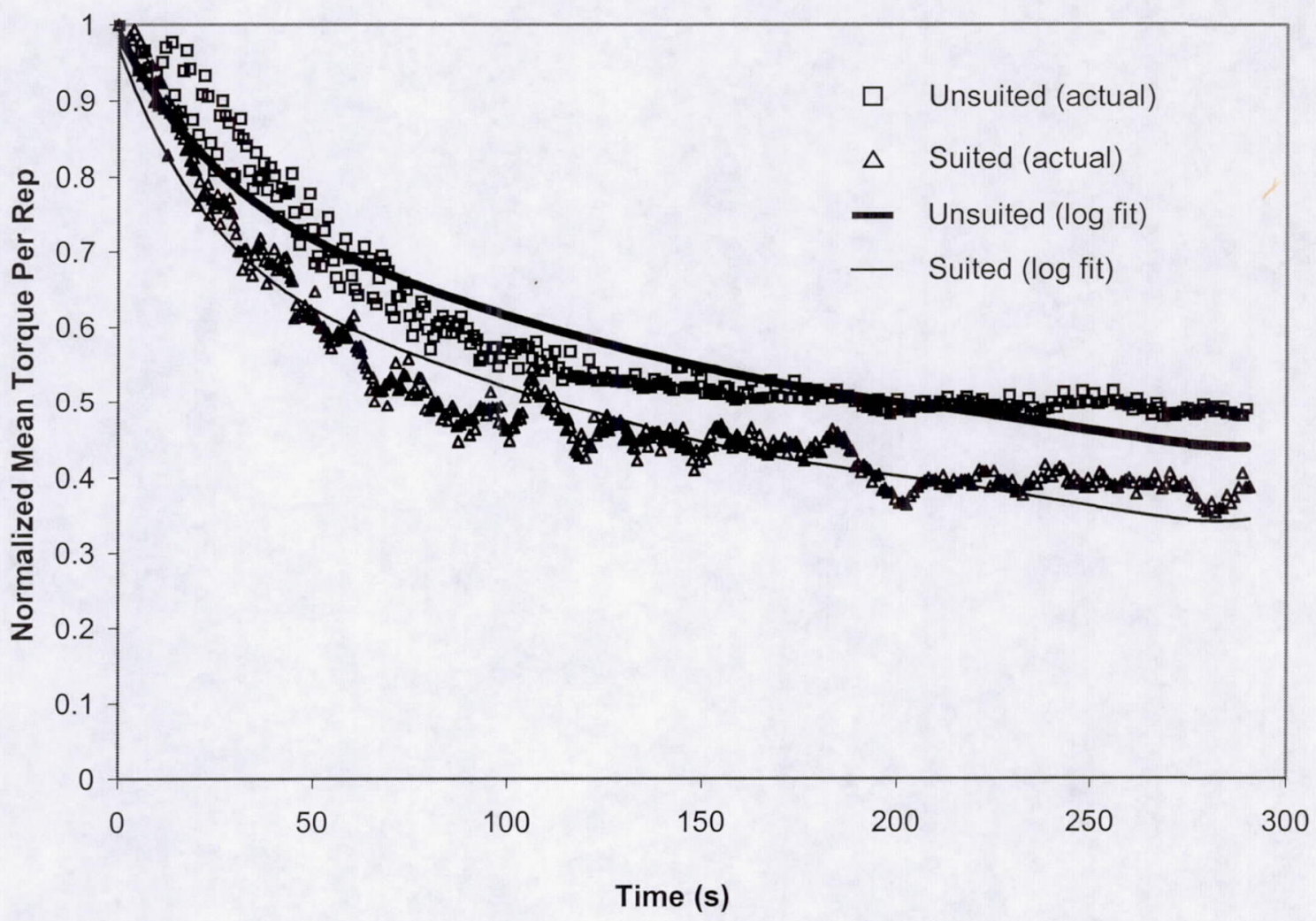

Figure 7. Normalized actual data and logarithmic curve fit for shoulder flexion at $100 \%$ MVT. 


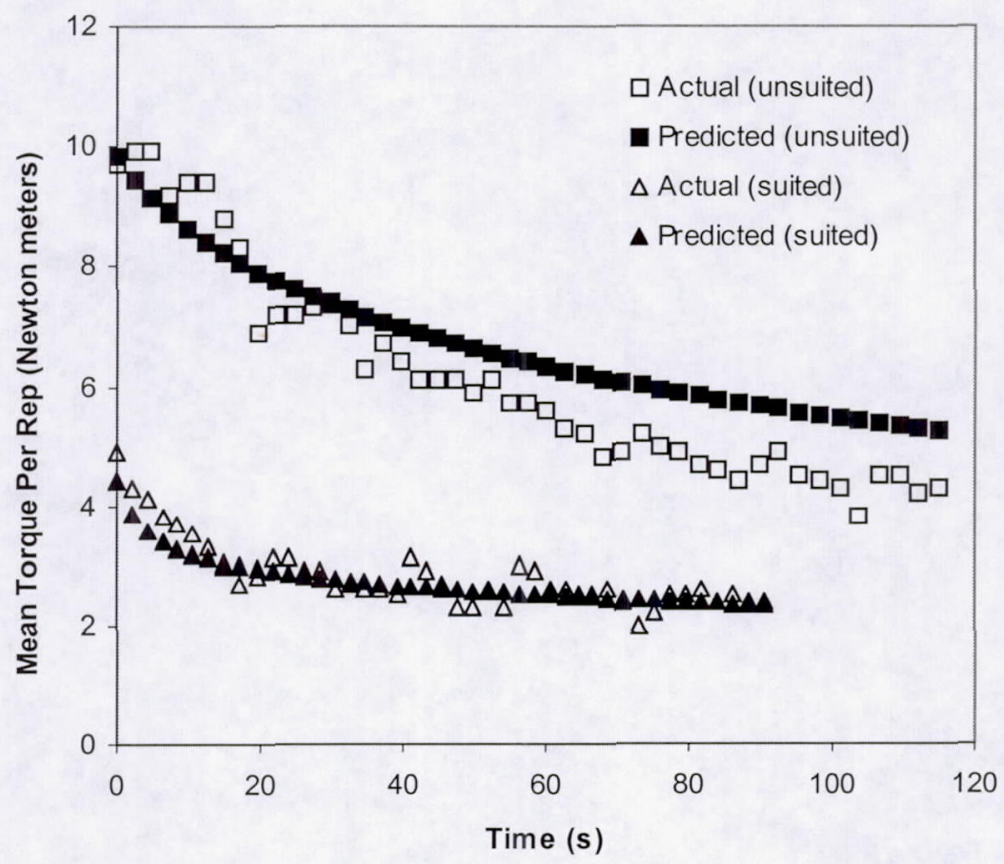

Figure 8. Actual and predicted torque for subject 2 during wrist extension at $100 \%$ MVT. 


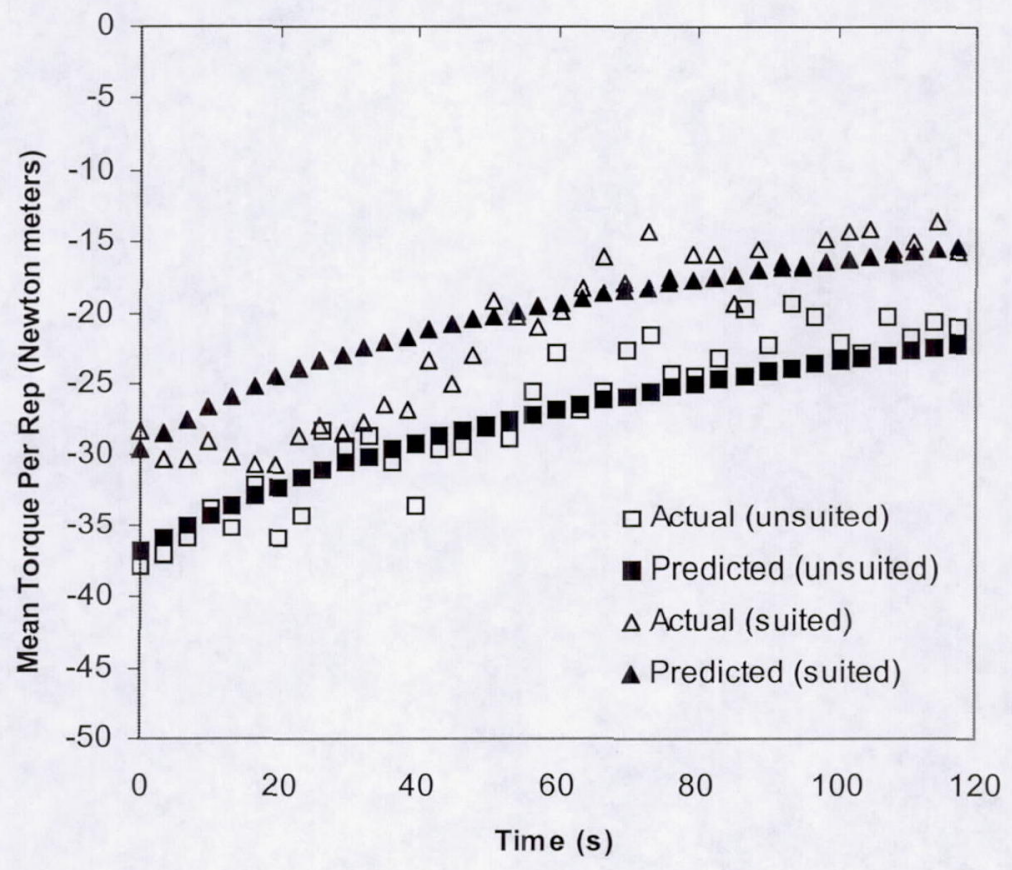

Figure 9. Actual and predicted torque for subject 3 during shoulder internal rotation at $80 \%$ MVT. 